DOI: 10 12962/i26130960 v5i3.27 $\mid$ Naskah Masuk 10-02-2021; $\quad$ Naskah Diulas 24-05-2021; $\quad$ Naskah Diterima 21-06-2021

\title{
NASKAH ORISINAL
}

\section{Produksi Batik Motif Kelautan di Kampung Jetis Sidoarjo}

\author{
Sujantoko*1 | Mahmud Mustain ${ }^{1}$ | Haryo Dwito \\ Armono $^{1}$ | Wahyudi $^{1}$ | Murdjito ${ }^{1}$ | Sholihin ${ }^{1}$ | Muhammad Zikra ${ }^{1}$ | Nani Kurniati ${ }^{2}$
}

\begin{abstract}
${ }^{1}$ Departemen Teknik Kelautan, Institut Teknologi Sepuluh Nopember, Surabaya, Indonesia

${ }^{2}$ Departemen Teknik Sistem dan Industri, Institut Teknologi Sepuluh Nopember, Surabaya, Indonesia
\end{abstract}

\section{Korespondensi}

*Sujantoko, Departemen Teknik Kelautan, Institut Teknologi Sepuluh Nopember,

Surabaya, Indonesia. Alamat e-mail:

sujantoko@oe.its.ac.id

\section{Alamat}

Laboratorium Hidrodinamika Bangunan Laut, Departemen Teknik Kelautan, Institut Teknologi Sepuluh Nopember, Surabaya, Indonesia

\begin{abstract}
Abstrak
Motif Batik merupakan hasil dari cipta, rasa dan karsa manusia yang diekspresikannya melalui kegiatan membatik. Setiap motif yang dibuat pada kain Batik memiliki nilai-nilai filosofis yang terkandung di dalamnya. Guna menumbuh-kembangkan motif Batik di Kampung Jetis Sidoarjo sebagai pusat kegiatan Batik tulis di Jawa Timur, perlu dijaga kelestariannya dengan cara menumbuhkan minat dan gairah pada generasi muda. Salah satu upaya adalah melalui pengenalan variasi Batik motif kelautan, mulai proses desain dan produksi Batik tersebut. Harapannya agar pengrajin dan masyarakat tetap menjadikan Batik sebagai produk unggulan dan warisan budaya Nusantara.
\end{abstract}

Kata Kunci:

filosofis, desain, motif batik kelautan, produksi, warisan budaya

\section{1 | PENDAHULUAN}

Batik adalah salah satu kesenian khas Indonesia yang telah hidup dan berkembang berabad-abad lamanya, serta memiliki nilainilai filosofis yang menjadi bagian dari kebudayaan Indonesia khususnya di Pulau Jawa. Bahkan pada tahun 2009, Batik telah ditetapkan menjadi warisan budaya dunia asal Indonesia oleh UNESCO. Secara bahasa, Batik berasal dari bahasa Jawa, yaitu amba dan nitik yang artinya menuliskan atau menorehkan titik-titik. Batik merupakan kain bergambar yang dibuat secara khusus dengan cara menuliskan malam pada kain dan pengolahannya diproses dengan cara tertentu [1].

Sidoarjo adalah salah satu kota yang memiliki potensi Batik yang patut diperhitungkan, yang terkenal dengan nama Kampoeng Batik Jetis . Di daerah tersebut, membatik telah menjadi bagian dari aktivitas sehari-hari dan menjadi tradisi budaya lokal masyarakat Jetis. Buktinya sekitar 90\% warga Kampoeng Jetis berprofesi sebagai pengrajin Batik pada tahun 1675.

Secara umum, motif Batik di Sidoarjo terdiri dari berbagai macam flora dan fauna, seperti udang-bandeng, burung merak, burung cipret, kupu-kupu, kembang suruh, dan lain-lain. Motif udang dan bandeng menjadi pakem Batik khas Sidoarjo, karena Sidoarjo adalah kota yang terkenal sebagai daerah penghasil udang dan bandeng. Dimana udang dan bandeng merupakan logo dari kota Sidoarjo. Selain itu, ada pula motif sekar jagad yang merupakan motif berbentuk ceplok berulang yang semuanya 
saling merapat dan berornamen bunga atau tanaman yang banyak dipakai pada batik Sekardangan. Potensi alam juga menjadi motif batik khas Sidoarjo, seperti pada batik Jetis yang berupa kembang bayem, beras wutah, dan kembang tebu. Selain itu hampir semua kain batik tulis Jetis bercorak dasar tidak lepas dari tiga corak tersebut sebagai identitas Sidoarjo.

Seiring dengan perkembangan zaman, batik Jetis pun mengalami perkembangan dalam segi motifnya, melalui inovasi dan improvisasi, yaitu tanpa meninggalkan motif yang sudah ada dan memunculkan motif-motif baru yang mengikuti perkembangan zaman dan pasar. Dimaksudkan untuk menunjang eksistensi batik Jetis dan permintaan pasar. Hal ini merupakan peluang pasar yang harus dimanfaatkan untuk meningkatkan taraf ekonomi dari pembatik itu sendiri. Peranan masyarakat di Sidoarjo dalam usaha melestarikan batik Jetis adalah membentuk paguyuban yang dinamakan dengan Paguyuban Batik Sidoarjo (PBS) pada tanggal 16 April 2008. Ide pembentukan paguyuban ini berasal dari kaum muda Jetis yang memiliki harapan besar kepada kelestarian batik Jetis itu sendiri dan menjadi budaya setempat yang bisa dibanggakan. Bahkan pemerintah juga ikut andil dalam meresmikan nama Kampoeng Batik Jetis oleh Bapak Win Hendrarso, selaku bapak Bupati Sidoarjo saat itu. Peresmian itu ditandai dengan adanya gapura Kampoeng batik Jetis yang dilengkapi dengan kombinasi motif Batik tulis Jetis dan ornamen canting batik.

Perkembangan batik yang mulai digemari masyarakat melahirkan potensi ekonomi yang mengubah sifat batik dari ekspresi seni menjadi sumber ekonomi masyarakat. Terjadinya perubahan ekonomi dan meningkatnya kebutuhan akan batik yang melambung tinggi menyebabkan industri rumah tangga ini berkembang menjadi industri yang dikelola oleh para pengusaha dan pedagang batik. Peralihan dari karya seni menjadi bentuk industri mengakibatkan batik mengalami banyak perubahan dan perkembangan. Kaum wanita menjadi sumber daya ekonomi yang sangat berarti dalam industri dan perdagangan batik.

Pemberdayaan pengusaha ini mendapat perhatian tinggi dalam kerangka pembangunan nasional terutama peningkatan pada kualitas sumber daya manusia dalam hal ini sumber daya manusia merupakan aset yang paling utama, dengan kualitas sumber daya manusia yang paripurna, maka akan mampu memainkan hubungan ekonomi internasional, memberi kontribusi perdamaian dunia yang pada hakekatnya melaksanakan empat tugas pokok yang diamanatkaan didalam Pembukaan Undang-Undang Dasar 1945.

\section{2 ～STRATEGI DAN TUJUAN KEGIATAN}

Pengenalan bidang Teknik Kelautan, Fakultas Teknologi Kelautan ITS, adalah mengenalkannya melalui motif Batik Kelautan sekaligus mulai proses desain dan produksi Batik tersebut. Diharapkan dengan mengaplikasikan motif-motif Batik yang bernuansa Teknologi Kelautan pada baju/pakaian sehari-hari, masyarakat luas dapat lebih mengenal bidang fokus keahlian dan lulusan Departemen Teknik Kelautan.

Secara umum kegiatan ini bertujuan untuk menjaga dan mempertahankan Batik sebagai warisan dan kekayaan budaya, memperkenalkan teknik Batik pada generasi muda, terutama generasi penerus pengrajin Batik di Kampung Jetis Sidoarjo dan menghasilkan motif Batik khas Teknik Kelautan yang ditujukan untuk sosialisasi Departemen Teknik Kelautan ITS. Dengan tercapainya tujuan-tujuan di atas, dampak positif yang diharapkan akan dapat diperoleh oleh masyarakat kampung Batik Jetis Sidoarjo adalah terjaganya Batik sebagai warisan dan kekayaan budaya, Teknik Batik dikenal dan dipelajari generasi muda terutama generasi penerus pengrajin Batik di Kampung Jetis Sidoarjo dan masyarakat pada umumnya.

\section{3 | PROSES DESAIN BATIK MOTIF KELAUTAN}

Proses pembuatan desain motif batik yang bercirikan kelautan dilakukan dengan langkah sebagai berikut:

a Menggali referensi dan literasi mengenai batik di berbagai refrensi Gambar 1 dan 2

b Eksplorasi bentuk atau isen-isen dengan menggambar sketsa di kertas menggunakan pensil Gambar 3

c Pembuatan pola rapor motif batik menggunakan sistem $\mathrm{OPQR}=$ Repeat satu langkah miring. Repeat pola hias dengan sistem rapor OPQR disusun menuju arah garis miring ke kanan atau kiri saja dengan sistem geser satu langkah. Sistem ini disebut juga "lereng" atau sistem "miring" Gambar 4 dan 5 


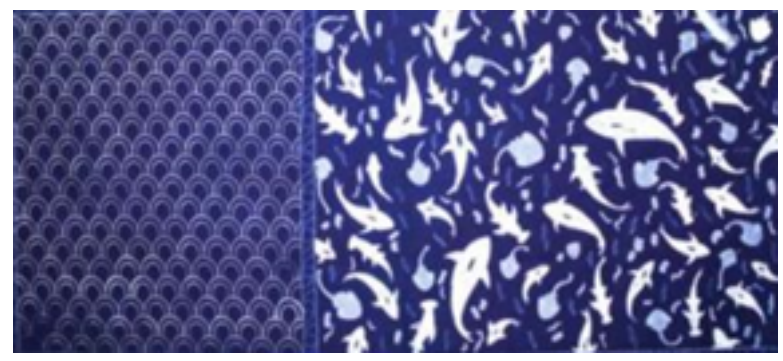

Gambar 1 Referensi batik [4]
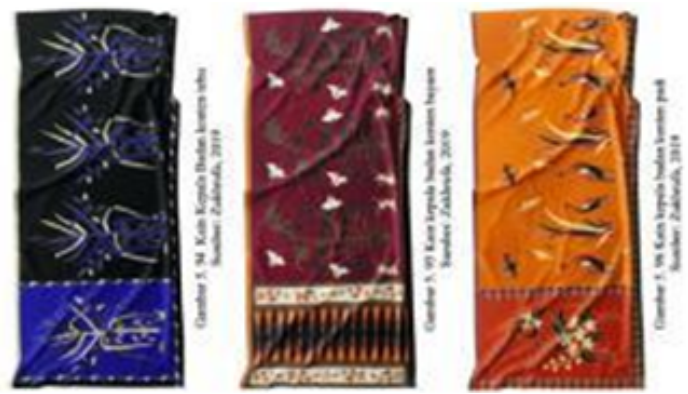

Gambar 2 Referensi batik [3]

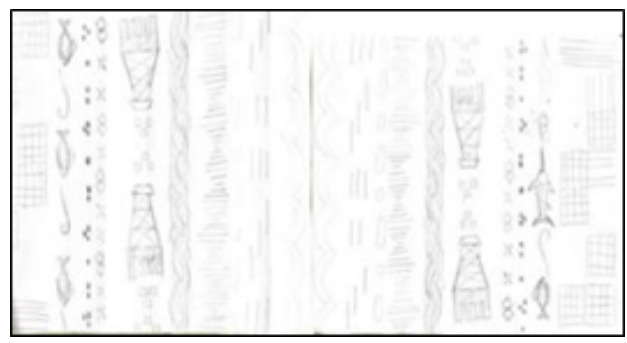

Gambar 3 Sketsa batik

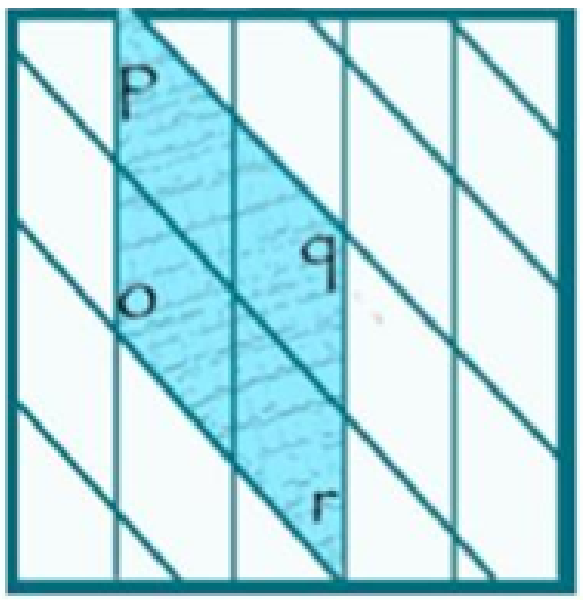

Gambar 4 . Pola OPQR [2] 


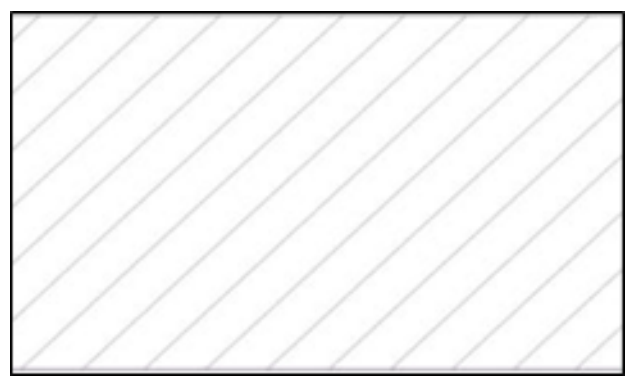

Gambar 5 Pola batik sistem miring

d Pembuatan bentuk secara digital menggunakan Adobe Illustrator. Dimulai dengan pengaturan pola, lalu ilustrasi bentuk per bentuk, dan pemilihan warna Gambar 6

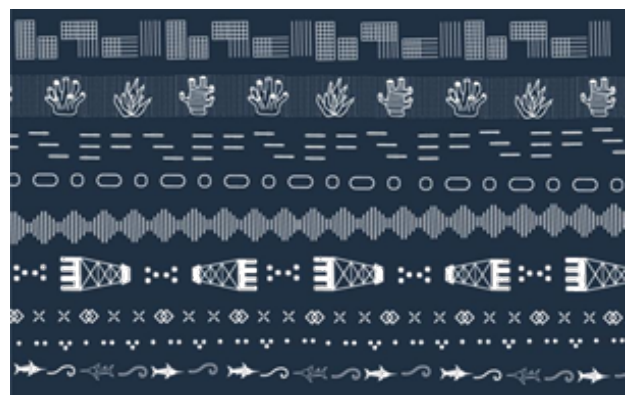

Gambar 6 Ilustrasi bentuk digital

e Pengisian bentuk terhadap pola batik, dengan melakukan pengisian secara repetisi Gambar 7

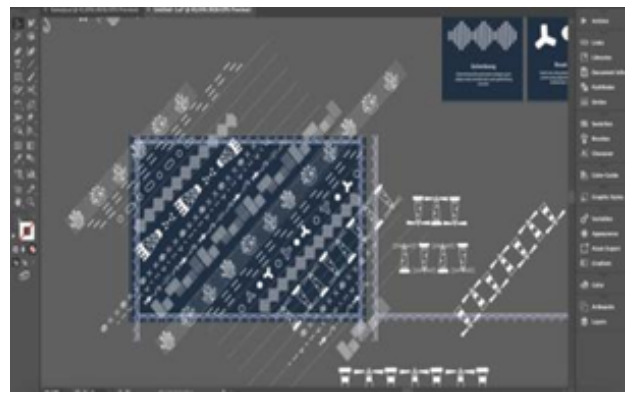

Gambar 7 Repetisi bentuk secara digital

f Hasil desain batik yang telah terpilih dengan keterangan pada tiap isen atau bentuk di dalam batik tersebut Gambar 8 dan 9

g Setelah batik terpilih, batik diaplikasikan pada kemeja lengan panjang dan lengan pendek Gambar 10 dan 11 


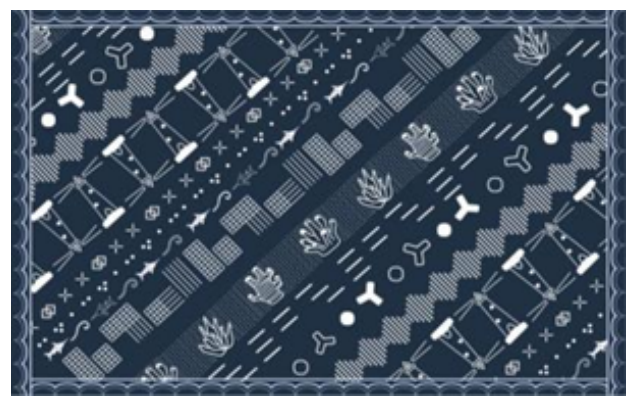

Gambar 8 Hasil desain terpilih

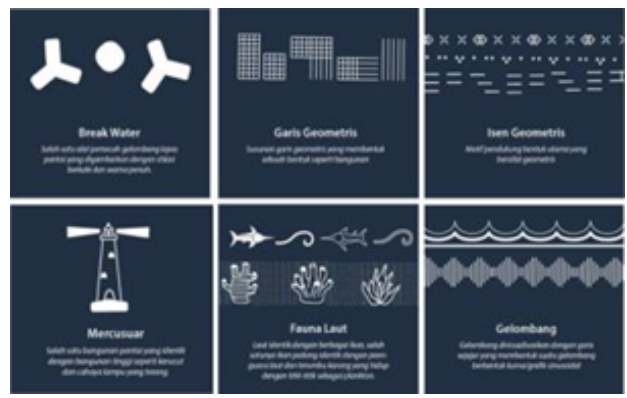

Gambar 9 Filosofi dan pengertian bentuk

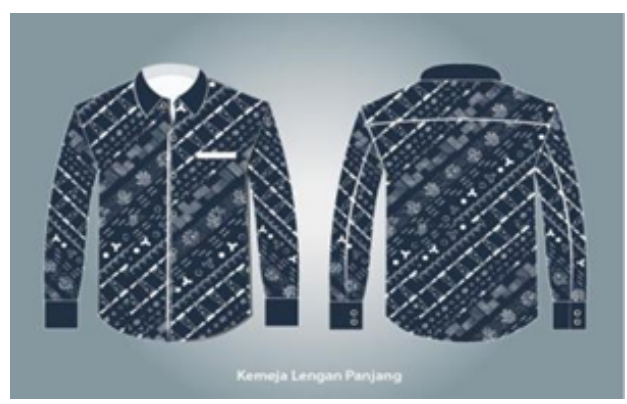

Gambar 10 Aplikasi kemeja lengan panjang

\section{4 | PROSES PEMBUATAN BATIK TULIS}

Batik Tulis merupakan Batik yang mempunyai nilai seni yang paling tinggi dibandingkan jenis batik-batik yang lain karnea proses pembuatannya yang rumit dan memakan waktu yang cukup lama. Secara singkat, proses pembuatan Batik Tulis adalah sebagai berikut:

1 Pengkhetelan - Batik itu dibuat diatas sebuah kain, namanya kain mori. Kain mori adalah kain tenun berwarna putih yang biasa digunakan sebagai kain untuk membatik Gambar 12 Kain Mori ini yang bagus dibuat dengan bahan katun, tapi ada juga yang polyester, sutra, dan rayon. Proses pengkhetelan adalah proses dimana kain Mori ini direbus dengan berbagai macam tumbuhan selama berhari-hari. Hasilnya lalu dikeringkan dan dinamakan kain Primisima. Kain Primisima adalah kain batik dengan kualitas nomor satu. Selain kain ini, ada juga kain Prima kualitasnya sedikit dibawahnya.

2 Menyorek - Proses penggambaran motif Batik ke kain. Gambar motif ini nya tidak diarsir atau diisi penuh. Biasanya gambar itu hanya dibuat garis tepinya saja. Garis tepi inilah nanti yang akan ditutup lilin dengan cara dicanting Gambar 13 


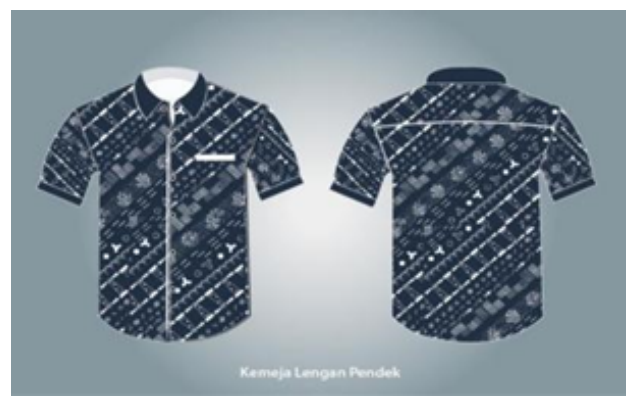

Gambar 11 Aplikasi kemeja lengan pendek

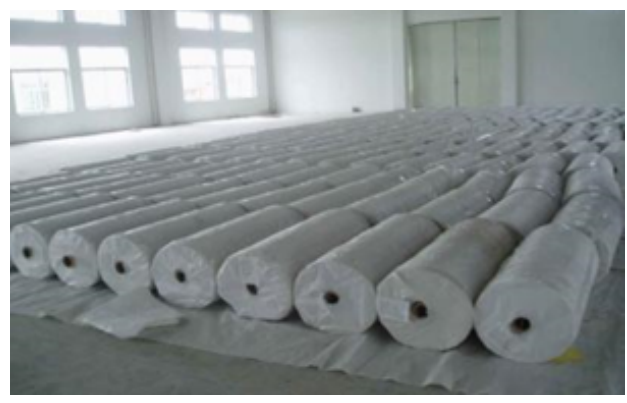

Gambar 12 Bahan dasar batik (kain mori)

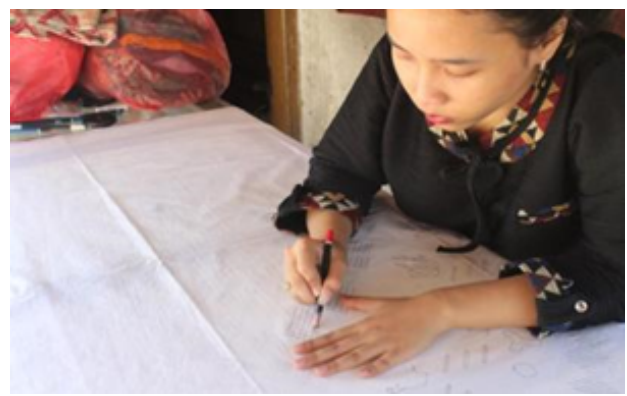

Gambar 13 Proses menyorek batik

3 Nyanting / Nglowong - Proses penutupan gambar motif batik dengan malam / lilin dengan menggunakan alat canting Gambar 14 Karena kain putih ini akan diberikan warna dasar (misalnya hitam), maka bagian-bagian gambar motif yang tidak ingin diwarnai hitam harus dilapisi. Biar mereka tetap putih saat lilin nya dilepas. Agar bagian yang dilapisi lilin bisa diwarnai dengan warna lain nanti. Proses nyanting ini berlangsung dua kali pada umumnya. Bagian depan yang pertama, lalu bagian belakang kain juga ikut dicanting. Ini dilakukan agar motif yang sudah digambar pensil pada bagian depan, tidak ikut diwarnai warna dasar pada bagian belakang. Karena bisa tembus.

4 Nembok - Untuk bagian-bagian lain yang tidak digambar dengan pensil, tapi ingin diberi warna lain, bagian ini harus ditembok dengan malam. Agar bagian tersebut tidak berwarna sama dengan warna dasar. Biasanya canting yang digunakan untuk nembok adalah canting dengan lubang yang lebih besar, sehingga pengerjaan menembok ini bisa lebih cepat selesai 15

5 Nyelup / Medel - Medel adalah proses pewarnaan dasar kain batik. Setiap daerah memiliki proses pencelupan sendirisendiri. Bahkan setiap pembatik di suatu daerah yang sama bisa memiliki proses pencelupan yang berbeda. Setelah semua bagian kain yang tidak ingin diwarnai sama dengan warna dasar, sudah dagian yang tidak tertutup lilin akan diwarnai dengan warna dasar. Kain mori ini akan dicelupkan ke sebuah wadah besar yang berisi pewarna dasar (misal warna hitam). 


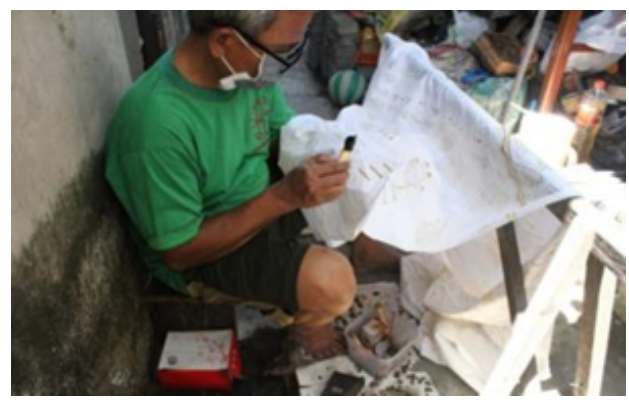

Gambar 14 Proses nyanting

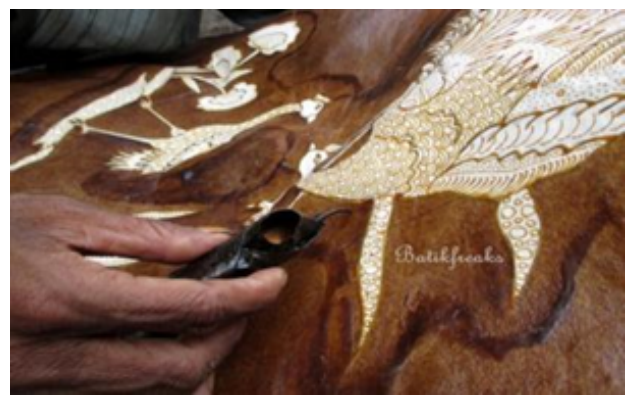

Gambar 15 Proses nembok

Pencelupan ini akan dilakukan berulang-ulang sampai warna hitam yang diinginkan sesuai dengan keinginan si pembatik Gambar 16 Namun, biasanya warna dasarnya dimulai dengan warna muda, kalau hitam mungkin dari warna biru atau abu-abu terlebih dahulu. Untuk menghindari hitamnya terlalu tua. Setelah dicelup berkali-kali, maka warna hitam akan diperoleh. Kalau sejak awal menggunakan warna hitam, takutnya hitamnya terlalu gelap padahal yang diperlukan adalah hitam yang lebih terang. Setelah pencelupan ini selesai, berarti warna dasar kain yang diinginkan sudah diperoleh. Maka langkah selanjutnya adalah mengeringkan kain dengan cara dijemur dengan diangin-anginkan saja Gambar 17

6 Ngerok / Nglorod - Proses meluruhkan lilin malam dari kain Mori. Bagian yang akan diwarnai beda dengan warna dasar (hitam), sekarang mau diwarnai. Misalnya motifnya mau diwarnai warna hijau. Maka sebelum diwarnai hijau, bagian yag tertutup lilin/malam harus dicairkan dengan proses nglorod atau ngerok Gambar 18 Lilin yang tadi dibubuhkan diatas motif sekarang dikerok dengan alat kerok, atau diluruhkan dengan cara direbus. Proses ini disebut $n g l o r o d$. Intinya prosesnya dibalik, gantian yang satu ditutup yang satu dibuka untuk diwarnai. Caranya tinggal merebus batik di air mendidih.

7 Nembok Bagian Kedua - Nah sebelum proses selanjutnya (nyelup kedua) dilakukan, bagian batik dengan warna dasar harus ditembok agar tidak berubah warnanya.

8 Nyelup / Medel Bagian Kedua - Kalau sudah selesai ngerok dan nembok, kemudian kembali lagi nyelup. Tapi sekarang dengan warna lain hingga motifnya berwarna sesuai keinginan.

9 Ngerok / Nglorod Kedua - Setelah semua warna yang diinginkan sudah terlukis pada kain, maka proses selanjutnya adalah nglorod lagi. Proses ini dilakukan untuk menghilangkan semua malam atau lilin yang tersisa pada kain Gambar 19 Caranya adalah dengan merebus kain di dalam air mendidih. Setelah proses nglorod ini selesai, maka selanjutnya kain harus dijemur sampai kering. Batik siap dijahit, atau langsung digunakan. Namun harus ingat, pada contoh ini proses pewarnaan hanya dua kali, pada aslinya, bisa 3, 4 sampai 5 kali tergantung berapa banyak warna yang ada pada batik itu.

Luaran yang telah diperoleh sampai selesainya kegiatan pengabdian masyarakat adalah sebagai berikut:

(a) Batik motif kelautan Gambar 20 dan 21 


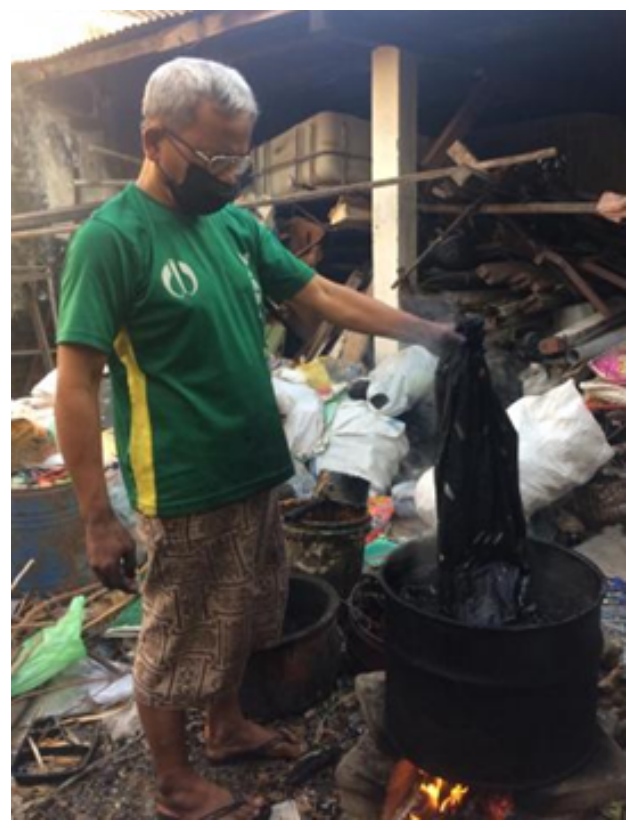

Gambar 16 Proses pencelupan kain batik pada warna dasar

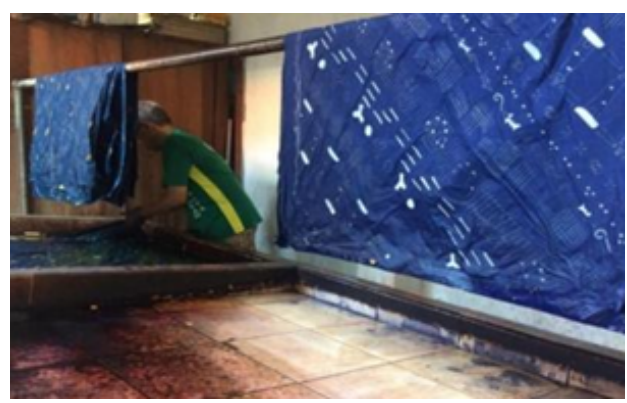

Gambar 17 Pengeringan kain batik

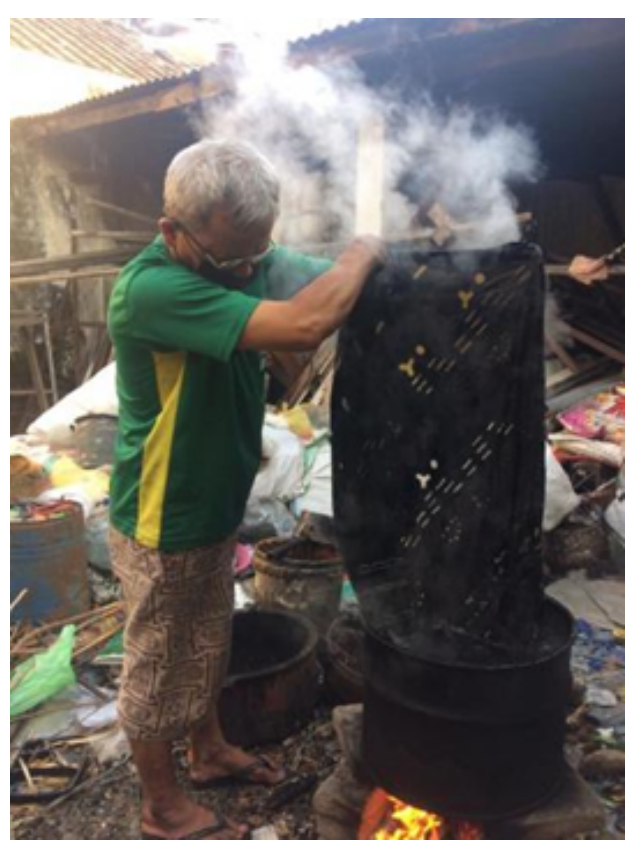

Gambar 18 Proses peluruhan lilin/malam 

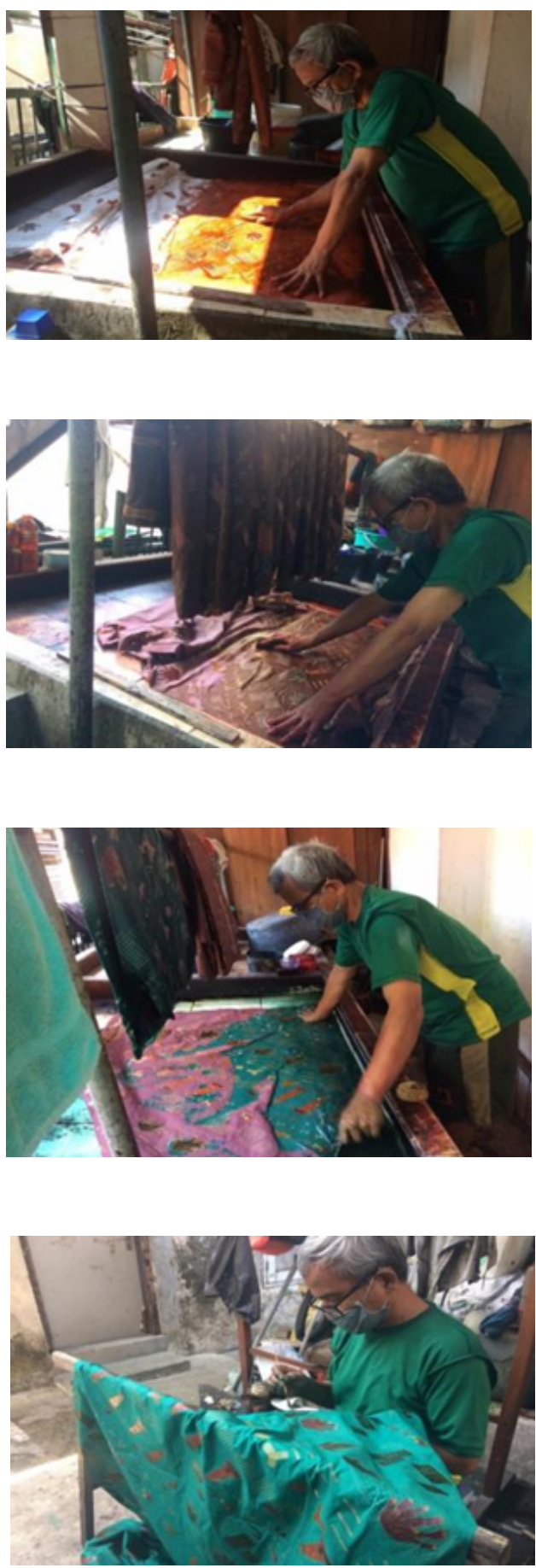

Gambar 19 Proses pewarnaan kedua

\section{5 | KESIMPULAN}

Motif Batik Kelautan telah berhasil dibuat dengan dua tipe. Tipe tersebut divariasikan dengan perbedaan warna sehingga dapat memberikan inovasi bagi pengrajin dan masyarakat dalam menghasilkan desain Batik yang baik. Sebagai Langkah awal desain ini diharapkan dapat memacu generasi muda dan pengrajin Batik untuk menemukan ide-ide baru lainnya dalam bidang Kelautan dan skaligus dapat mengenalkan Kelautan ke masyarakat secara lebih luas. 


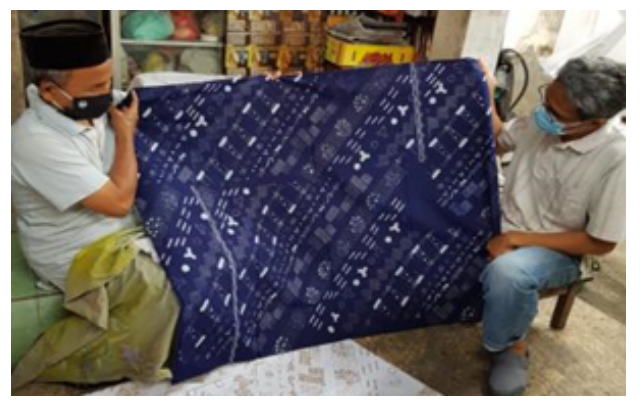

Gambar 20 Batik motif kelautan tipe-1

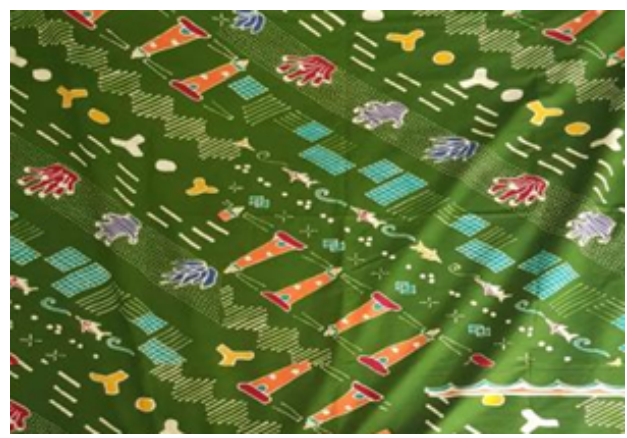

Gambar 21 Batik motif kelautan tipe-2

\section{6 | UCAPAN TERIMA KASIH}

Pengabdian masyarakat ini di biayai dengan Dana Departemen Teknik Kelautan, Fakultas Teknologi Kelautan, dan dikoordinasi oleh Direktorat Riset dan Pengabdian Masyarakat (DRPM) Institut Teknologi Sepuluh Nopember (ITS).

\section{Pustaka}

[1] Saroni Asikin. Ungkapan batik di Semarang: motif batik Semarang 16. Citra Prima Nusantara Semarang, 2008.

[2] Rahyono. "Perwujudan Batik Gubahan kajian perkembangan ragam hias dan fungsi batik larangan Surakarta". Surakarta, Indonesia, 2004.

[3] Riopike. Karya Batik Kain Panjang dengan Tema Pencemaran Ekosistem Laut di Indonesia. 2019. URL: https://twitter. com/riopike\%5C\%20/status/1159090945465307136?s=21\%5C\%20 (accessed: 04.08.2020).

[4] Adinda Zukhrufa. "Perancangan Eksplorasi Gaya Gambar Motif Asli Batik Jetis Sidoarjo". in: (2019).

Cara mengutip artikel ini: Sujantoko, Mustain M., Armono H. D., Wahyudi, Murdjito, Zikra M., Kurniati N., (2021), Produksi Batik Motif Kelautan di Kampung Jetis Sidoarjo, Sewagati: Jurnal Pengabdian Kepada Masyarakat, 5(3):217-226. 